\title{
Hypoxia-mediated histone acetylation and expression of $N$-myc transcription factor dictate aggressiveness of neuroblastoma cells
}

\author{
JITKA POLJAKOVÁ ${ }^{1}$, TOMÁŠ GROH ${ }^{1}$, ŽANETA OMANA GUDINO $^{1}$, JAN HRABĚTA $^{2}$, \\ LUCIE BOŘEK-DOHALSKÁ ${ }^{1}$, RENÉ KIZEK ${ }^{3,4}$, HELENA DOKTOROVÁ ${ }^{2}$, \\ TOMÁŠ ECKSCHLAGER ${ }^{2}$ and MARIE STIBOROVÁ ${ }^{1}$
}

\author{
${ }^{1}$ Department of Biochemistry, Faculty of Science, Charles University, 12840 Prague 2; ${ }^{2}$ Department of Pediatric \\ Hematology and Oncology, 2nd Medical School, Charles University and University Hospital Motol, 15006 Prague 5; \\ ${ }^{3}$ Department of Chemistry and Biochemistry, Faculty of Agronomy, Mendel University in Brno, 61300 Brno; \\ ${ }^{4}$ Central European Institute of Technology, Brno University of Technology, 61600 Brno, Czech Republic
}

Received November 26, 2013; Accepted December 23, 2013

DOI: 10.3892/or.2014.2999

\begin{abstract}
Cells of solid malignancies generally adapt to entire lack of oxygen. Hypoxia induces the expression of several genes, which allows the cells to survive. For DNA transcription, it is necessary that DNA structure is loosened. In addition to structural characteristics of DNA, its epigenetic alterations influence a proper DNA transcription. Since histones play a key role in epigenetics, changes in expression levels of acetylated histones $\mathrm{H} 3$ and $\mathrm{H} 4$ as well as of hypoxiainducible factor- $1 \alpha$ (HIF-1 $\alpha$ ) in human neuroblastoma cell lines cultivated under standard or hypoxic conditions $(1 \%$ $\mathrm{O}_{2}$ ) were investigated. Moreover, the effect of hypoxia on the expression of two transcription factors, $c$-Myc and $N$-myc, was studied. Hypoxic stress increased levels of acetylated histones H3 and H4 in UKF-NB-3 and UKF-NB-4 neuroblastoma cells with $N$-myc amplification, whereas almost no changes in acetylation of these histones were found in an SK-N-AS neuroblastoma cell line, the line with diploid $N$-myc status. An increase in histone $\mathrm{H} 4$ acetylation caused by hypoxia in UKF-NB-3 and UKF-NB-4 corresponds to increased levels of $\mathrm{N}$-myc transcription factor in these cells.
\end{abstract}

\section{Introduction}

Neuroblastoma is an embryonal cancer of the postganglionic sympathetic nervous system, which most commonly arises in the adrenal gland. It is the most frequent malignant disease of infancy and is a major cause of mortality from neoplasia at this age (1). These tumors are biologically heterogeneous,

Correspondence to: Professor Marie Stiborová, Department of Biochemistry, Faculty of Science, Charles University, Albertov 2030, 12840 Prague 2, Czech Republic

E-mail: stiborov@natur.cuni.cz

Key words: hypoxia, neuroblastoma, histone acetylation, $N$-myc expression with cell populations differing in their genetic programs, maturation stage and malignant potential. As neuroblastoma cells seem to have the capacity to differentiate spontaneously in vivo and in vitro (2), their heterogeneity may affect treatment outcome, in particular the response to apoptosis induced by chemotherapy. Low-risk neuroblastoma is one of the rare human malignancies that are known to demonstrate spontaneous regression in infants from an undifferentiated state to a benign ganglioneuroma, whereas high-risk neuroblastoma grows relentlessly and may be rapidly fatal. Prognosis of the high-risk form of this type of cancer is poor, since drug resistance arises in the majority of the patients initially responding well to chemotherapy (3).

Approximately $40 \%$ of patients suffering from neuroblastoma belong to the high-risk group. Unfavorable tumors are characterized by structural chromosomal changes, including deletions of $1 p$ or 11q, unbalanced gain of $17 \mathrm{q}$ and/ or amplification of the $N-m y c$ proto-oncogene. Among them, amplification of the $N-m y c$ is a marker for high-risk neuroblastoma (3). Indeed, $N$ - myc overexpression in neuroblastomas with amplified $N-m y c$ is associated with poor prognosis (3). Among the prognostic indicators of neuroblastoma, $N$-myc amplification is strongly associated with advanced disease stages, rapid tumor progression and the poorest disease outcome. $N-m y c$ amplification occurs in $\sim 20$ to $25 \%$ of all neuroblastoma cases and it leads to $N$-myc overexpression at both the mRNA and protein levels $(4,5)$. However, the high $N$-myc expression confers the opposite biological consequence in neuroblastoma, depending on $N$-myc gene status. Indeed, high-level of $N$-myc expression is associated with favorable outcome in neuroblastoma lacking $N-m y c$ amplification. Forced expression of $N$-myc significantly suppresses growth of neuroblastoma cells lacking $N$-myc amplification by inducing apoptosis and enhancing favorable neuroblastoma gene expression. Hence, it may be postulated that high-level $N$-myc expression in neuroblastoma lacking $N$-myc amplification results in a benign phenotype (4). Whereas $N$-myc overexpression in neuroblastoma cells with $N$-myc amplification induces the malignant phenotype of these neuroblastoma cells (3), overexpression of the other genes of the Myc family 
induces unrestricted cell proliferation, inhibits differentiation, cell growth, angiogenesis, reduces cell adhesion, metastasis and induces genomic instability (6). In human neuroblastoma cells with inducible $N$-myc expression, the $N$-myc increases apoptosis induced by cytostatics. Furthermore, neuroblastoma cells with $N$ - myc amplification can resist treatment only when there is additional dysfunction in the apoptosis pathways (7). Another mechanism of drug resistance in neuroblastoma cells, to which $N$-myc may contribute, is the regulation of $\mathrm{ABC}$ transporter genes (8).

A reduction in the normal level of tissue oxygen tension, hypoxia, produces cell death if severe or prolonged (9). In solid tumors it is a consequence of structurally and functionally disturbed microcirculation and the deterioration of diffusion conditions (10). Although hypoxia is toxic to both cancer cells and normal cells, cancer cells undergo genetic and adaptive changes that allow them to survive and even proliferate in the hypoxic environment (9). Therefore, tumor hypoxia appears to be strongly associated with tumor progression and resistance to chemo- and radio-therapy, and has thus become an important issue in tumor physiology and cancer treatment (10). However, the mechanisms explaining how cancer cells can survive hypoxia more efficiently than normal cells remain to be explored.

The epigenetic structure of DNA in chromatin plays a role in the origin of neuroblastomas (11). Dynamic formation of DNA leads not only to transcription of different genes but DNA is also more accessible for DNA-targeted chemotherapeutics. Approximately 75 genes are described as epigenetically affected in neuroblastoma cells (12). DNA hypermethylation and gene silencing is generally associated with the abundance of deacetylated histones, the other essential actors of epigenetic mechanisms (13). Indeed, histones are key players in epigenetics and their status dictates accessibility of chromatin DNA for binding of transcription factors that regulates DNA transcription (14).

The core histones $\mathrm{H} 3, \mathrm{H} 4, \mathrm{H} 2 \mathrm{~A}$ and $\mathrm{H} 2 \mathrm{~B}$ around which 147 base pairs of DNA are wrapped are predominantly globular except for their $N$-terminal tails, which are unstructured (15). There are at least eight distinct types of modifications. One of the most important histone modifications is acetylation of lysine residues, which regulates various cell processes such as transcription, repair, replication and condensation of DNA (15). Histone acetylation is regulated by the equilibrium of two groups of enzymes: histone acetyltransferases (HATs) and histone deacetylases (HDACs) (13). Watson et al showed significant alterations in the global levels of histone acetylation and DNA methylation in response to chronic hypoxic exposure, where cells were permanently maintained at $1 \%$ oxygen, i.e., specifically consistent and sustained global increases in H3K9 acetylation and DNA methylation in the absence of hypoxia-inducible factor hypoxia-inducible factor-1 $\alpha(\mathrm{HIF}-1 \alpha)(16)$. Therefore, since acetylation of histones is an important epigenetic mark that may be influenced by hypoxia, investigation of changes in expression levels of acetylated histones $\mathrm{H} 3$ and $\mathrm{H} 4$ in human neuroblastoma cell lines by hypoxia is one of the aims of the present study. The effect of hypoxia on amounts of HIF-1 $\alpha$ protein was also examined. In addition, levels of $N$-myc protein and another member of the Myc family of transcription factors,
$c$-Myc, may be influenced by the chromatin structure that is dictated by acetylation of histones $\mathrm{H} 3$ and $\mathrm{H} 4$ and recruit other co-factors to activate gene expression (17-19). Therefore, the present study also investigated the effect of hypoxia on the relationships between acetylation of histones $\mathrm{H} 3$ and $\mathrm{H} 4$ and expression of $N$-myc and $c$-Myc in neuroblastoma cells. Since heterogeneity of neuroblastoma cells may affect their responsibility to hypoxia, three neuroblastoma cell lines were tested in the present study: UKF-NB-3, UKF-NB-4 and SK-N-AS cell lines.

\section{Materials and methods}

Chemicals and materials. AA mix (acrylamide:bisacrylamide 29:1), natrium butyrate, natrium deoxycholate, natrium dodecyl sulfate (SDS), 1,2-bis(dimethylamino)ethane (TEMED), polyoxyethylene-sorbitan monolaurate (Tween-20), ammonium peroxodisulfate (APS) and glycine were purchased from Sigma-Aldrich (St. Louis, MO, USA). 4-(2-Hydroxyethyl)1-piperazineethanesulfonic acid (HEPES), dithiothreitol (DTT), phenylmethylsulfonyl fluoride (PMSF) were obtained from Gibco-BRL (Life Technologies, Carlsbad, CA, USA). Phosphate-buffered saline (PBS), trypsin and SeeBlue ${ }^{\circledR}$ Plus2 Pre-Stained Standard were purchased from Invitrogen (Life Technologies, Carlsbad, CA, USA). Natrium hydrogen carbonate, hydrogen chloride and methanol were acquired from Penta (Prague, Czech Republic). Tris [1,1,1-Tris (hydroxymethyl) aminomethane (TRIS)] was obtained from Lachema (Brno, Czech Republic). Blotting Grade Blocker non-fat dry milk was purchased from Bio-Rad (Hercules, CA, USA). All these and other chemicals used in the experiments were of analytical purity or better.

Cell cultures. The human neuroblastoma cells lines UKF-NB-3 and UKF-NB-4 with $N-m y c$ amplification, established from bone marrow metastases of high-risk neuroblastoma, were a gift from Professor J. Cinatl Jr (J.W., Goethe University, Frankfurt, Germany). SK-N-AS cells with diploid $N$-myc status were purchased from American Type Culture Collection (ATCC, Manassas, VA, USA). Cells were cultivated in Iscove's modified Dulbecco's medium (IMDM) (Lonza, Basel, Switzerland), supplemented with $10 \%$ fetal calf serum and 2 mM L-glutamine, (PAA Laboratories, Pasching, Austria) at $37^{\circ} \mathrm{C}$ and $5 \% \mathrm{CO}_{2}$. For experiments with hypoxia, a hypoxic chamber purchased from Billups-Rothenberg (Del Mar, CA, USA) was prepared with an atmosphere containing $1 \% \mathrm{O}_{2}$, $5 \% \mathrm{CO}_{2}$ and $94 \% \mathrm{~N}_{2}$.

Estimation of contents of acetylated histones $\mathrm{H} 3$ and $\mathrm{H} 4$ in neuroblastoma cells. Cell pellets were re-suspended in $10 \mathrm{mM}$ HEPES buffer $\mathrm{pH} 7.9$ containing $1.5 \mathrm{mM} \mathrm{MgCl}$, $10 \mathrm{mM} \mathrm{KCl}, 0.5 \mathrm{mM}$ dithiothreitol and $1.5 \mathrm{mM}$ PMSF for preparation of acid extraction of proteins as introduced in the anti-H4 antibody datasheet. To each sample, hydrochloric acid was added to a final concentration of $0.2 \mathrm{M}$. The samples were incubated on ice for $30 \mathrm{~min}$ and centrifuged at $11,000 \mathrm{x} \mathrm{g}$ for $10 \mathrm{~min}$ at $4^{\circ} \mathrm{C}$. The supernatant fraction, which contains the acid soluble proteins, was dialyzed against $0.1 \mathrm{M}$ acetic acid, twice for $1 \mathrm{~h}$ each, and against distilled water for $2 \mathrm{~h}$ and overnight. Protein concentrations were 

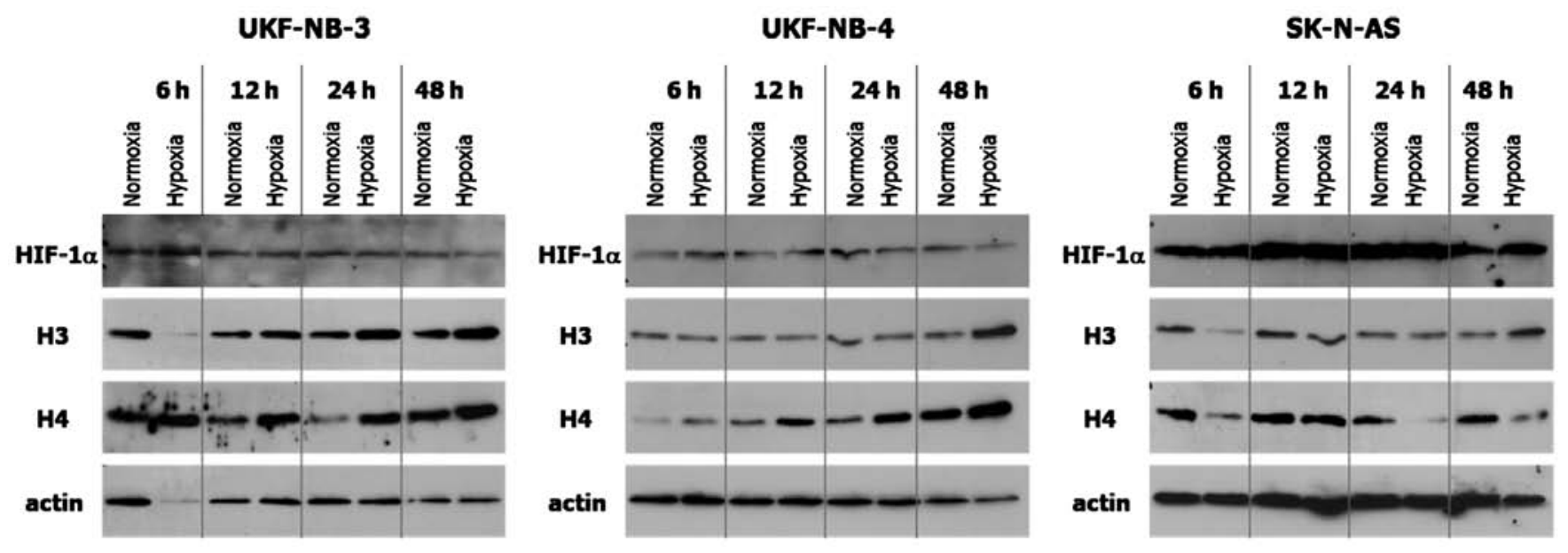

Figure 1. The effect of hypoxia on expression of HIF-1 $\alpha$ and acetylated histones $\mathrm{H} 3$ and $\mathrm{H} 4$ in human neuroblastoma cell lines determined by western blotting. Actin was used as loading control. HIF-1 $\alpha$, hypoxia-inducible factor-1 $\alpha$.

assessed using the DC protein assay (Bio-Rad) with serum albumin as a standard. Five and/or $15 \mu \mathrm{g}$ of extracted proteins were subjected to SDS-PAGE electrophoresis $(20,21)$ on a $17 \%$ gel for analysis of histone $\mathrm{H} 3$ and/or $\mathrm{H} 4$ acetylation, respectively. After migration, proteins were transferred to a nitrocellulose membrane and incubated with 5\% non-fat milk to block non-specific binding. The membranes were then exposed to specific rabbit polyclonal anti-H3 $(1: 10,000)$ and anti-H4 (1:20,000) (both from Upstate, Lake Placid, NY, USA), antibodies overnight at $4^{\circ} \mathrm{C}$. Membranes were washed and exposed to peroxidase-conjugated anti-IgG secondary antibodies $(1: 3,000)$ and the antigen-antibody complex was visualized by enhanced chemiluminescence detection system according to the manufacturer's instructions (Immun-Star HRP Substrate) (both from Bio-Rad), using X-ray film from MEDIX XBU (Foma, Hradec Králové, Czech Republic). Antibody against actin (1:1,000; Sigma, St. Louis, MO, USA) was used as loading control.

HAT and HDAC activity. Activity of HATs and HDACs was assessed according to the manufacturer's instructions by HAT Activity and HDAC Activity Colorimetric Assay kits (BioVision, Milpitas, CA, USA). Briefly, $68 \mu \mathrm{l}$ of assay mix containing $40 \mu \mathrm{l}$ 2X HAT assay buffer, $5 \mu \mathrm{l}$ HAT substrate, $15 \mu \mathrm{l}$ HAT substrate II and $8 \mu \mathrm{l}$ NADH generating enzyme were added to $50 \mu \mathrm{g}$ of nuclear extract in $40 \mu \mathrm{l}$ of distilled water. Each well of the 96-well plate was mixed. The plate was incubated at $37^{\circ} \mathrm{C}$ for $1 \mathrm{~h}$ and then read in a VersaMax ${ }^{\mathrm{TM}}$ microplate reader (Molecular Devices, Sunnyvale, CA, USA) at $440 \mathrm{~nm}$. Alternatively, 50-200 $\mu \mathrm{g}$ of nuclear extract were diluted in $85 \mu \mathrm{l}$ of distilled water. Ten microliters of 10X HDAC assay buffer and $5 \mu \mathrm{l}$ of an HDAC colorimetric substrate was added to each well. After thorough mixing, plates were incubated at $37^{\circ} \mathrm{C}$ for $1 \mathrm{~h}$. The reaction was stopped by adding $10 \mu \mathrm{l}$ of Lysine developer. After mixing well, the plate was incubated at $37^{\circ} \mathrm{C}$ for $30 \mathrm{~min}$. Samples were read in plate reader VersaMax ${ }^{\mathrm{TM}}$ microplate reader at $400 \mathrm{~nm}$.

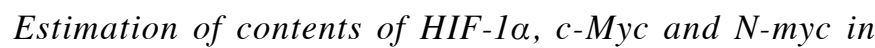
neuroblastoma cells. To determine the expression of HIF-1 $\alpha$,
c-Myc and N-myc proteins, cell pellets were resuspended in $25 \mathrm{mM}$ Tris- $\mathrm{HCl}$ buffer $\mathrm{pH} 7.6$ containing $150 \mathrm{mM} \mathrm{NaCl}$, $1 \%$ detergent Igepal ${ }^{\circledR}$ CA-630 (Sigma), $1 \%$ sodium deoxycholate and $0.1 \%$ SDS and with solution of Complete ${ }^{\mathrm{TM}}$ (protease inhibitor cocktail tablet; Roche, Basel, Switzerland) at concentrations described by the provider. The samples were incubated for $60 \mathrm{~min}$ on ice and thereafter centrifuged for $20 \mathrm{~min}$ at $14,000 \mathrm{x} \mathrm{g}$ and $4^{\circ} \mathrm{C}$. Supernatant was used for additional analysis. Protein concentrations were assessed using the DC protein assay (Bio-Rad) with serum albumin as a standard. Then, $50 \mu \mathrm{g}$ of extracted proteins were subjected to SDS-PAGE electrophoresis on an $11 \%$ gel for analysis of HIF-1 $\alpha$, c-Myc and N-myc protein expression. After migration, proteins were transferred to a nitrocellulose membrane and incubated with $5 \%$ non-fat milk to block non-specific binding. The membranes were then exposed to specific rabbit polyclonal anti-HIF-1 $\alpha$ (1:3,000; Zymed Life Technologies, Carlsbad, CA, USA), rabbit monoclonal anti-c-Myc (1:500) antibodies and to specific mouse monoclonal anti-N-myc (1:1,000) (both from Santa Cruz Biotechnology, Inc., Dallas, TX, USA) antibody overnight at $4^{\circ} \mathrm{C}$. Membranes were washed and exposed to peroxidase-conjugated anti-IgG secondary antibodies (1:3,000; Bio-Rad), and the antigen-antibody complex was visualized by enhanced chemiluminescence detection system according to the manufacturer's instructions (Immun-Star HRP Substrate), using X-ray film from MEDIX XBU. Antibody against actin (1:1,000; Sigma) was used as loading control.

Cell cycle analysis. To determine cell cycle distribution analysis, $5 \times 10^{5}$ cells were plated in $60 \mathrm{~mm}$ dishes and treated under hypoxic conditions for $24 \mathrm{~h}$. After treatment, the cells were collected by trypsinization, stained with DNA PREP reagent kit (Beckmann Coulter, Fullerton, CA, USA), that contains permeabilization reagent and propidium iodide solution with RNase, according to the manufacturer's instructions, and at least 30,000 cells were analyzed by flow cytometry on a FACSCalibur cytometer (BD, San Jose, CA, USA). The data were analyzed using ModFit LT software (Verity Software House, Topsham, ME, USA). 
A

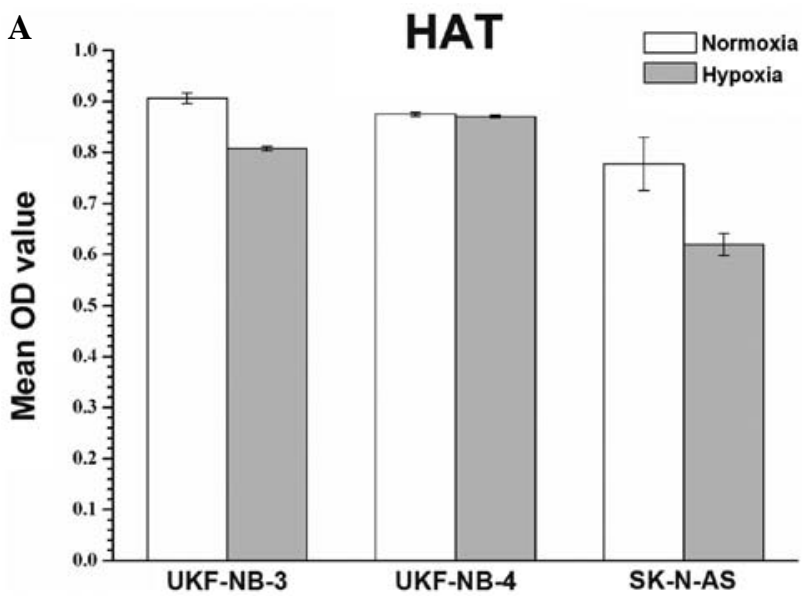

B

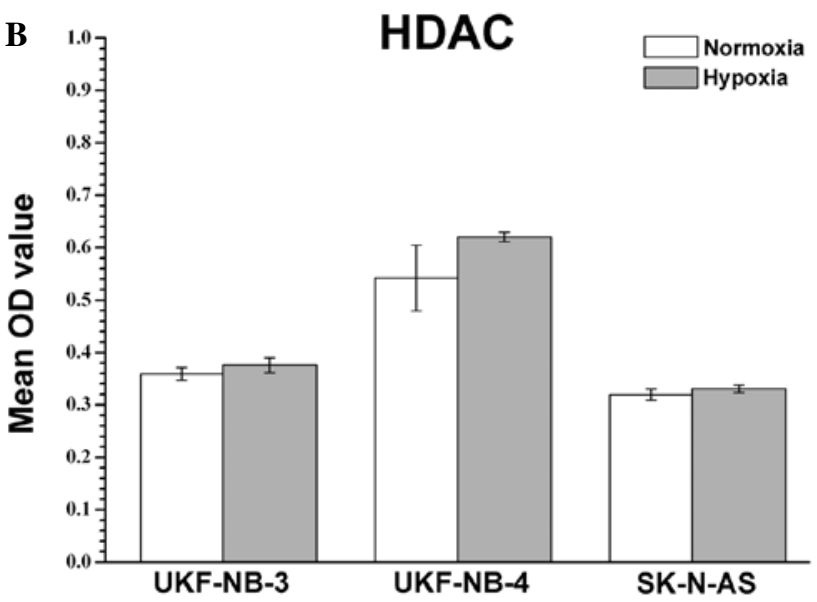

Figure 2. The effect of hypoxia on activities of (A) histone acetyltransferases (HATs) and (B) histone deacetylases (HDACs) in neuroblastoma cells. Hypoxia, $24 \mathrm{~h}$ exposure to $1 \% \mathrm{O}_{2}$.

\section{Results and Discussion}

The effect of hypoxia on acetylation of histone $\mathrm{H} 3$ and $\mathrm{H} 4$ in neuroblastoma cells. Epigenetic processes are involved in causation and progression of many types of malignancies, including neuroblastoma. Therefore, we decided to explore how commonly emerging state in neoplasia regions, hypoxia affects chromatin-associated proteins and post-translational modifications of histones regulated transcription. Using western blotting, different levels of acetylated histones H3 and $\mathrm{H} 4$ in individual human neuroblastoma cell lines cultivated under normoxic or hypoxic conditions $\left(1 \% \mathrm{O}_{2}\right)$ were found. Cultivation of the tested neuroblastoma cells for 6 , 12,24 or $48 \mathrm{~h}$ in hypoxia increased acetylation of histone $\mathrm{H} 4$ in UKF-NB-3 and UKF-NB-4 cell lines, the lines derived from high-risk neuroblastomas with $N$-myc amplification. In contrast to these results, decreased levels of histone $\mathrm{H} 4$ acetylation after $24 \mathrm{~h}$ exposure to hypoxia were detected in an SK-N-AS neuroblastoma cell line having diploid $N-m y c$ status. Therefore, it may be assumed that an increase in acetylation of histone $\mathrm{H} 4$ is related to $\mathrm{N}-\mathrm{myc}$ amplification. Acetylation of the only histone $\mathrm{H} 3$ was increased under hypoxic conditions in a UKF-NB-3 cell line. With the exception of $48 \mathrm{~h}$ hypoxia, where histone $\mathrm{H} 3$ acetylation was increased in UKF-NB-4 and SK-N-AS, almost no changes in histone $\mathrm{H} 3$ acetylation were produced by hypoxia in UKF-NB-4 and SK-N-AS cells (Fig. 1).

Activity of HATs and HDACs. Although the activities of HATs were slightly lowered by $24 \mathrm{~h}$ hypoxia cultivation of UKF-NB-3 and SK-N-AS cells, no effect of such conditions of cultivation was found on these enzymes in a UKF-NB-4 cell line. In addition, essentially no differences in activities of HDACs were produced by hypoxia in tested neuroblastoma cells (Fig. 2). These findings suggest that increased acetylation of histones $\mathrm{H} 3$ and $\mathrm{H} 4$ in UKF-NB-3 and UKF-NB-4 neuroblastoma cells and decreased acetylation of the histones in SK-N-AS cells (see Fig. 1) is not directly connected with activities of these enzymes and follows from the other, still unknown, mechanism(s).

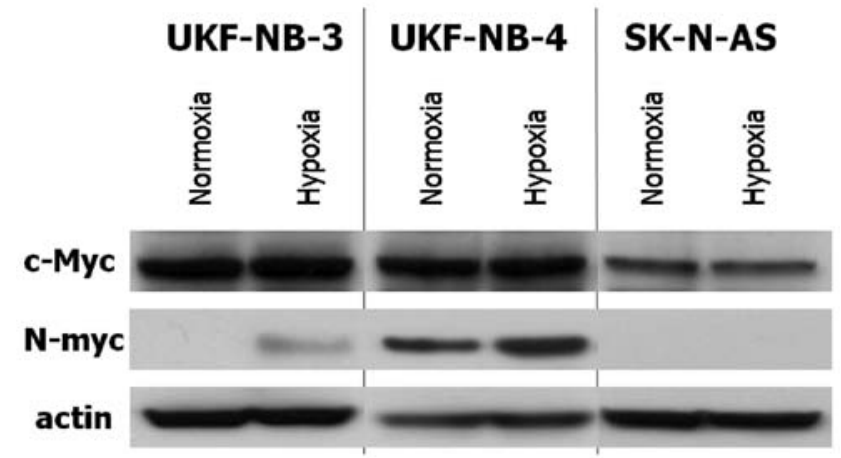

Figure 3. The effect of hypoxia on expression of $c$-Myc and $N$-myc proteins in human neuroblastoma cell lines determined by western blotting. Actin was used as loading control.

Hypoxia influences expression of $N$-myc but not $c-M y c$ in neuroblastoma cells. Different levels of $N$-myc protein were found in either studied neuroblastoma cell line cultivated both under hypoxic and normoxic (standard) conditions. Of all tested cell lines cultivated under standard conditions, the $\mathrm{N}$-myc protein was expressed in detectable amounts only in the UKF-NB-4 cells (Fig. 3). However, hypoxic conditions of cultivation of the neuroblastoma cells $(24 \mathrm{~h})$ resulted in increased expression of protein of this transcription factor in these neuroblastoma cells and even in expression of this protein in UKF-NB-3 cells. However, $N$-myc protein was undetectable in the SK-N-AS line, neither in normoxia nor in hypoxia. The increased levels of proto-oncogene $N$-myc protein mediated by hypoxia in UKF-NB-3 and UK-NB-4 neuroblastoma cell lines with $N-m y c$ amplification were paralleled with an increase in histone $\mathrm{H} 4$ acetylation in these cells (compare Figs. 1 and 3). Histone's lysine residue acetylation leads to decreased interactions between distinct chromatin fibres and to a decondensation of chromatin and increased accessibility of DNA to the transcriptional machinery due to the DNA uncoiling (22). These results indicate that hypoxia induces an increase in gene transcription activation in the neuroblastoma cells with $N$-myc amplification. Since $N$-myc 


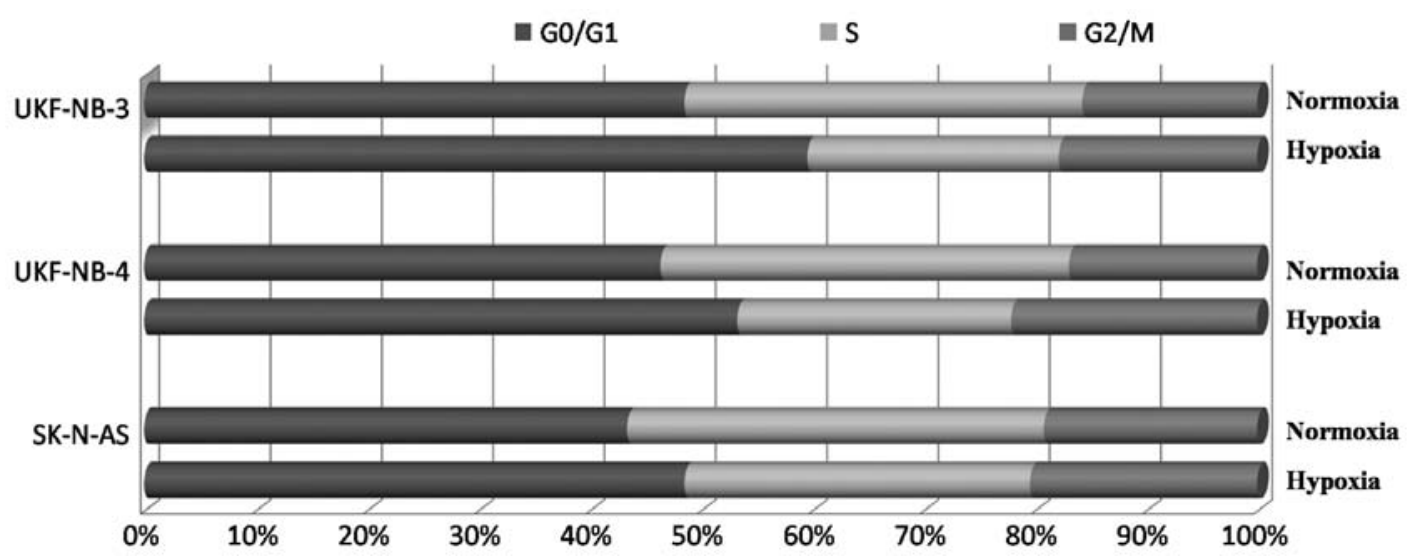

Figure 4. Cell cycle distribution in human neuroblastoma cell lines assessed by flow cytometry; the effect of 24 h hypoxia on cell cycle of these cells in comparison with the standard cultivation conditions.

also both activates and represses the expression of several miRNAs and long non-coding RNAs that play important roles in neuroblastoma progression (23), an increase in its expression may be involved in the higher aggressive property of these neuroblastoma cells. Indeed, regardless of cell cultivation conditions, no $N$-myc expression was detected by western blotting in an SK-N-AS cell line that lacked $N$-myc amplification. It may be speculated that increased acetylation of histone $\mathrm{H} 4$ caused by hypoxia is involved in cancer progression of neuroblastoma cells with $N$-myc amplification. Since most tumors contain hypoxic area, $N$-myc overexpression induced by hypoxia may decrease response of neuroblastoma with $N$-myc amplification to chemotherapy.

In contrast to $N$-myc protein, essentially no differences in $c$-Myc protein expression were found in neuroblastoma cells cultivated under normoxic or hypoxic conditions (Fig. 3), which corresponds to the findings of Huang et al, who found an inverse relationship between $N-m y c$ and $c-M y c$ expression in various neuroblastoma derived cell lines and that both $\mathrm{N}-\mathrm{myc}$ and $c-M y c$ overexpression accelerates tumor cell proliferation and tumorigenesis directly through $B M I I$ (polycomb ring finger oncogene) gene transcription (24).

Influence of hypoxia on HIF-1a protein expression in neuroblastoma cells. The transcription factor HIF-1 $\alpha$ is a key mediator of the cellular response to hypoxia affecting expression of many genes that may inhibit apoptosis (25). Although HIF-1 $\beta$ is constitutively expressed in the nucleus, HIF-1 $\alpha$ is maintained at low levels under normoxic conditions (26). In the presence of oxygen, the HIF-1 $\alpha$ subunits undergo hydroxylation by oxygen-dependent prolyl hydroxylases allowing their binding to the von Hippel-Lindau (VHL) protein and targeting for ubiquitination and degradation (27). Overexpression of HIF- $1 \alpha$ protein has been described in many different types of human malignancies, but not in benign tumors or normal tissues $(28,29)$. In addition, overexpression of HIF-1 $\alpha$ correlates with p53 accumulation, cell proliferation, and direct activation of vascular endothelial growth factor (VEGF) promoter, which suggests important roles for HIF-1 $\alpha$ in cancer progression $(28,30)$. As in other tumors, overexpression of HIF-1 $\alpha$ protein has been found in all neuroblastoma cell lines tested in this study, with the highest being in an SK-N-AS cell line. Only a slight increase in levels of HIF-1 $\alpha$ protein was found after $6 \mathrm{~h}$ of cultivation of all tested neuroblastoma cells in hypoxia, but at longer intervals (12, 24 and 48 h), no such increase was observed (Fig. 1).

Hypoxia affects cell cycle distribution of neuroblastoma cells. The cell cycle distribution of tested neuroblastoma cells measured by flow cytometry was slightly altered by oxygen deprivation $\left(1 \% \mathrm{O}_{2}\right.$, for $\left.24 \mathrm{~h}\right)$ in comparison to the cell cycle distribution of cells cultivated under the standard (aerobic) conditions (Fig. 4). An increase in the G0/G1 phase with a concomitant decrease in the $\mathrm{S}$ phase of the cell cycle was produced by cultivation of all tested human neuroblastoma cells for $24 \mathrm{~h}$ under hypoxic conditions. It is evident that cancer cells cultivated under low levels of oxygen $\left(1 \% \mathrm{O}_{2}\right)$ require more time to be entered into the $\mathrm{S}$ phase of the cell cycle. This may be a consequence of a shift of cell metabolism from the oxidative to anaerobic one. It is known that the anaerobic metabolism is less effective in production of energy essential for biosynthesis of components of DNA such as deoxynucleoside triphosphates needed for biosynthesis of DNA in the $\mathrm{S}$ phase of the cell cycle. Another mechanism of decreased proliferation in hypoxia is the effect of HIF-1 $\alpha$ that inhibits DNA replication and induces cell cycle arrest in various cell types (31).

In conclusion, in the present study, we have demonstrated that hypoxic stress increased levels of acetylated histones H3 and $\mathrm{H} 4$ in UKF-NB-3, and histone H4 in UKF-NB-4 neuroblastoma cell lines derived from high-risk neuroblastoma, both cell lines possessing $N$-myc amplification. In contrast, almost no changes in acetylation of these histones were found in an SK-N-AS neuroblastoma cell line with diploid $N$-myc status.

Hypoxia-induced acetylation of histones in tested neuroblastoma cell lines was not associated with expression of the transcription factor HIF-1 $\alpha$ in these cells or with changes in HAT and HDAC activities. Although HIF-1 $\alpha$ protein was overexpressed in all neuroblastoma cell lines tested in this study, essentially no differences in its expression were produced by hypoxia. Of note, the highest levels of HIF-1 $\alpha$ protein were found in SK-N-AS neuroblastoma cells. 
The increase in histone $\mathrm{H} 4$ acetylation mediated by hypoxia in UKF-NB-3 and UKF-NB-4 neuroblastoma cell lines was paralleled with the increased levels of proto-oncogene $N$-myc protein expression in these neuroblastoma cells with $N-m y c$ amplification. In addition, expression of this protein was not detectable in an SK-N-AS neuroblastoma cell line, the line with diploid $N-m y c$ status. These findings suggest that acetylation of histone $\mathrm{H} 4$ in neuroblastoma cells with $N$-myc amplification determines expression of transcription factor $N$-myc. The results showing the hypoxia-induced increase in levels of histone acetylation found in this study in UKF-NB-3 and UKF-NB-4 neuroblastoma cells are the opposite of those demonstrated by Li and Costa (19), who examined the effect of hypoxia on human A549 lung carcinoma cells. These authors found that exposure of this cancer cell line to hypoxia caused a decrease in acetylation of histones H3 and H4. Moreover, the authors showed that a decreased level of $c$-Myc expression was consistent with the effect of hypoxia on global histone H4 acetylation in A549 cells (19). These findings, which are different from those found in the present study, may be caused by the different type of cancer cells they used, human A549 lung carcinoma cells, in which $N-m y c$ amplification is missing. A decrease in acetylation of $\mathrm{H} 3$ and $\mathrm{H} 4$ by hypoxia in SK-N-AS neuroblastoma cells, a line without $N$-myc amplification, was also observed in the present study.

The results found in the present study indicate that insight into changes in levels of acetylated histones $\mathrm{H} 3$ and $\mathrm{H} 4$ and $N$-myc protein generated by hypoxic stress in the studied neuroblastoma cell lines may be important for partial explanation of the aggressive property of these cells. This is true predominantly for UKF-NB-4 neuroblastoma cells, the line with $N$-myc amplification and high P-glycoprotein expression that was prepared from chemoresistant recurrence $(32,33)$. The $N$-myc protein is overexpressed in these cells and is even induced by hypoxia in these and UKF-NB-3 cells. An increased acetylation of histones allows $N$-myc to be easily bound to DNA, thereby inducing efficient transcription processes resulting finally in accelerated cell growth and proliferation. Therefore, among the genetic changes which allow high-risk neuroblastoma cells with $N$-myc amplification to survive hypoxia and to efficiently grow and proliferate under these conditions, may be the high expression of $N-m y c$ proto-oncogene and its induction by hypoxia.

\section{Acknowledgements}

The present study was supported by GACR (P301/10/0356), Charles University in Prague (635712/2012, 620612/2012 and UNCE 204025/2012) and MH CZ-DRO, University Hospital Motol, Prague, Czech Republic 00064203.

\section{References}

1. Maris JM and Matthay KK: Molecular biology of neuroblastoma. J Clin Oncol 17: 2264-2279, 1999.

2. Morgenstern BZ, Krivoshik AP, Rodriguez V and Anderson PM: Wilms' tumor and neuroblastoma. Acta Paediatr Suppl 93: 78-85, 2004.

3. Brodeur GM: Neuroblastoma: biological insights into a clinical enigma. Nat Rev Cancer 3: 203-216, 2003.
4. Tang XX, Zhao H, Kung B, Kim DY, Hicks SL, Cohn SL, Cheung NK, Seeger RC, Evans AE and Ikegaki N: The MYCN enigma: significance of $M Y C N$ expression in neuroblastoma. Cancer Res 66: 2826-2833, 2006.

5. Lutz W and Schwab M: In vivo regulation of single copy and amplified N-myc in human neuroblastoma cells. Oncogene 15: 303-315, 1997.

6. Westermann F, Muth D, Benner A, Bauer T, Henrich KO, Oberthuer A, Brors B, Beissbarth T, Vandesompele J, Pattyn F, Hero B, König R, Fischer M and Schwab M: Distinct transcriptional MYCN/c-MYC activities are associated with spontaneous regression or malignant progression in neuroblastomas. Genome Biol 9: R150, 2008.

7. Fulda S, Lutz W, Schwab M and Debatin KM: MycN sensitizes neuroblastoma cells for drug-induced apoptosis. Oncogene 18: 1479-1486, 1999.

8. Porro A, Haber M, Diolaiti D, Iraci N, Henderson M, Gherardi S, Valli E, Munoz MA, Xue C, Flemming C, Schwab M, Wong JH, Marshall GM, Della Valle G, Norris MD and Perini G: Direct and coordinate regulation of ATP-binding cassette transporter genes by Myc factors generates specific transcription signatures that significantly affect the chemoresistance phenotype of cancer cells. J Biol Chem 285: 19532-19543, 2010.

9. Harris AL: Hypoxia - a key regulatory factor in tumour growth. Nat Rev Cancer 2: 38-47, 2002.

10. Höckel M and Vaupel P: Tumor hypoxia: definitions and current clinical, biologic, and molecular aspects. J Natl Cancer Inst 93: 266-276, 2001.

11. Furchert SE, Lanvers-Kaminsky C, Juürgens H, Jung M, Loidl A and Frühwald MC: Inhibitors of histone deacetylases as potential therapeutic tools for high-risk embryonal tumors of the nervous system of childhood. Int J Cancer 120: 17871794, 2007.

12. Decock A, Ongenaert M, Vandesompele J and Speleman F: Neuroblastoma epigenetics: from candidate gene approaches to genome-wide screenings. Epigenetics 6: 962-970, 2011.

13. Santini V, Gozzini A and Ferrari G: Histone deacetylase inhibitors: molecular and biological activity as a premise to clinical application. Curr Drug Metab 8: 383-393, 2007.

14. Portela A and Esteller M: Epigenetic modifications and human disease. Nat Biotechnol 28: 1057-1068, 2010.

15. Kouzarides T: Chromatin modifications and their function. Cell 128: 693-705, 2007.

16. Watson JA, Watson CJ, McCrohan AM, Woodfine K, Tosetto M, McDaid J, Gallagher E, Betts D, Baugh J, O'Sullivan J, Murrell A, Watson RW and McCann A: Generation of an epigenetic signature by chronic hypoxia in prostate cells. Hum Mol Genet 8: 3594-3604, 2009.

17. Frank SR, Schroeder M, Fernandez P, Taubert S and Amati B: Binding of c-Myc to chromatin mediates mitogen-induced acetylation of histone $\mathrm{H} 4$ and gene activation. Genes Dev 15: 2069-2082, 2001.

18. Frank SR, Parisi T, Taubert S, Fernandez P, Fuchs M, Chan HM, Livingston DM and Amati B: MYC recruits the TIP60 histone acetyltransferase complex to chromatin. EMBO Rep 4: 575-580, 2003.

19. Li Q and Costa M: c-Myc mediates a hypoxia-induced decrease in acetylated histone H4. Biochimie 91: 1307-1310, 2009.

20. Stiborová M, Martínek V, Rýdlová H, Hodek P and Frei E: Sudan $I$ is a potential carcinogen for humans: evidence for its metabolic activation and detoxication by human recombinant cytochrome P450 1A1 and liver microsomes. Cancer Res 62: 5678-5684, 2002.

21. Poljaková J, Eckschlager T, Kizek R, Frei E and Stiborová M: Electrochemical determination of enzymes metabolizing ellipticine in thyroid cancer cells - a tool to explain the mechanism of ellipticine toxicity to these cells. Int J Electrochem Sci 8: 1573-1585, 2013.

22. Gut $\mathrm{P}$ and Verdin E: The nexus of chromatin regulation and intermediary metabolism. Nature 502: 489-498, 2013.

23. Buechner J and Einvik C: N-myc and noncoding RNAs in neuroblastoma. Mol Cancer Res 10: 1243-1253, 2012.

24. Huang R, Cheung NK, Vider J, Cheung IY, Gerald WL, Tickoo SK, Holland EC and Blasberg RG: MYCN and MYC regulate tumor proliferation and tumorigenesis directly through BMI1 in human neuroblastomas. FASEB J 25: 4138$4149,2011$. 
25. Liu XH, Yu EZ, Li YY and Kagan E: HIF-1 $\alpha$ has an antiapoptotic effect in human airway epithelium that is mediated via Mcl-1 gene expression. J Cell Biochem 97: 755-765, 2006.

26. Wang GL, Jiang BH, Rue EA and Semenza GL: Hypoxiainducible factor 1 is a basic-helix-loop-helix-PAS heterodimer regulated by cellular $\mathrm{O}_{2}$ tension. Proc Natl Acad Sci USA 92: 5510-5514, 1995

27. Adamski J, Price A, Dive C and Makin G: Hypoxia-induced cytotoxic drug resistance in osteosarcoma is independent of HIF-1Alpha. PloS One 8: e65304, 2013.

28. Zhong H, De Marzo AM, Laughner E, Lim M, Hilton DA, Zagzag D, Buechler P, Isaacs WB, Semenza GL and Simons JW: Overexpression of hypoxia inducible factor $1 \alpha$ in common human cancers and their metastases. Cancer Res 59: 5830$5835,1999$.

29. Talks KL, Turley H, Gatter KC, Maxwell PH, Pugh CW, Ratcliffe PJ and Harris AL: The expression and distribution of the hypoxia-inducible factors HIF- $1 \alpha$ and HIF- $2 \alpha$ in normal human tissues, cancers, and tumor associated macrophages. Am J Pathol 157: 411-421, 2000.
30. Kwon HJ, Kim MS, Kim MJ, Nakajima H and Kim KW: Histone deacetylase inhibitor FK228 inhibits tumor angiogenesis. Int J Cancer 97: 290-296, 2002.

31. Hubbi ME, Kshitiz, Gilkes DM, Rey S, Wong CC, Luo W, Kim DH, Dang CV, Levchenko A and Semenza GL: A nontranscriptional role for HIF- $1 \alpha$ as a direct inhibitor of DNA replication. Sci Signal 6: ra10, 2013.

32. Bedrnicek J, Vicha A, Jarosova M, Holzerova M, Cinatl Jr J, Michaelis M, Cinatl J and Eckschlager T: Characterization of drug-resistant neuroblastoma cell lines by comparative genomic hybridization. Neoplasma 52: 415-419, 2005.

33. Poljakova J, Hrebackova J, Dvorakova M, Moserova M, Eckschlager T, Hrabeta J, Göttlicherova M, Kopejtkova B, Frei E, Kizek R and Stiborova M: Anticancer agent ellipticine combined with histone deacetylase inhibitors, valproic acid and trichostatin A, is an effective DNA damage strategy in human neuroblastoma. Neuro Endocrinol Lett 32 (Suppl 1): 101-116, 2011. 